\title{
Strengthening public sector records management through the Information Regulator in South Africa
}

\author{
Makutla Mojapelo \\ University of South Africa \\ mojapmg@unisa.ac.za
}

Received: 18 December 2019

Revised: 18 January 2020

Accepted: 16 April 2020

\begin{abstract}
The Information Regulator in South Africa is charged with the responsibility to regulate access to information. The implementation of the access to information legislation is heavily dependent on proper records management in the public sector; however, there is consensus among researchers that records are poorly managed in the public sector. The purpose of the study is to describe how records management in the public sector in South Africa can be strengthened through the Information Regulator. This qualitative study utilised document analysis and literature review for data collection. The study was limited to one mandate of the Information Regulator, which is the Promotion of Access to Information Act (PAIA). The PAIA was analysed to contextualise the correlation between the Act and records management in the public sector. The study found that the successful implementation of specific sections of the PAIA is dependent on proper records management. While it is acknowledged that the Information Regulator is making inroads into records management space, the study recommends that extra effort needs to be made to strengthen collaboration with the National Archives and Records Service of South Africa, which is charged with a statutory regulatory role for records management in public bodies. A framework was developed to outline the role that the Information Regulator can play to strengthen records management service in the public sector.
\end{abstract}

Keywords: Information Regulator, access to information, records management, public sector, national archives

\section{Introduction}

The public sector in South Africa is characterised by ineffective record-keeping, which ultimately has a detrimental impact on the protection of various fundamental human rights such as the right of access to information. Several scholars such as Mojapelo (2017), Mojapelo and Ngoepe (2017), Khumalo and Baloyi (2019) emphasised the close connection between public sector record-keeping and the right of access to information. For example, Mojapelo and Ngoepe (2017) point out that effective systems of record-keeping are important for the right of access to information to be realised. Furthermore, in a study conducted by Khumalo and Baloyi (2019) to examine how records and archives in Eastern and Southern African Branch of the International Council on Archives (ESARBICA) would benefit from the implementation of freedom of information legislation, it was found that freedom of information could benefit records and archives in the region by encouraging the development of proper record-keeping 
systems, formalisation and standardisation of records management practice and continuous training of records practitioners.

The poor state of record-keeping in the public sector has a direct impact on the mandate of the Information Regulator, which is the promotion of access to information. For example, in the case SA Airlink (Pty) Limited $v$ the Mpumalanga Tourism and Park Agency (MTPA) and others, it was revealed that poor records management and information systems practices continued to frustrate the right to information. As reported by the South African History Archives (SAHA) (2012), the case involved a request by SA Airlink for a copy of an agreement and related documentation between MTPA and Comair for flights between OR Tambo and Kruger Mpumalanga Airport. The court found that no valid grounds for refusing the applicant's request for records existed and that the applicant was entitled to the records it sought in terms of section 82 of PAIA.

Some of the challenges faced by public sector record-keeping emanate from a lack of adequate support from the National Archives and Records Service of South Africa (NARSSA), as underscored by Archival Platform (2015). The current study identified the Information Regulator as the relevant organisation to rescue the embattled NARSSA. Traditionally, the overall roles and responsibilities pertaining to the monitoring of records management service in the public sector were left to the control of the NARSSA; however, significant changes have been observed, with various state-owned entities making inroads into the records management space to assist NARSSA. For example, the Auditor-General of South Africa (AGSA) and NARSSA signed a memorandum of understanding (MoU) as part of the plan to promote the friendly collaboration between the two institutions. However, the signing of the MoU did not come as a surprise, as Ngoepe and Keakopa (2011) had already identified the AGSA as one of the institutions in South Africa that can make a contribution to records management in the public sector. In a study to investigate the contribution of selected chapter 9 institutions (the AGSA and the South African Human Rights Commission (SAHRC)), Mojapelo and Ngoepe (2017) concurred with Ngoepe and Keakopa (2011) that the AGSA has a role to play in improving the status of records management in the public sector in South Africa.

Section 32 of the Constitution makes specific provision for the right of access to information (Archival Platform 2015). According to section 32 of the Constitution, everyone has the right to:

Access any information held by the state and any information that is held by another person and that is required for the exercise or protection of any rights.

The Constitution further provides that national legislation be enacted to give effect to the constitutional right of access to information, hence the passing of PAIA. Public archives are expected to be key role players in promoting access to information. For example, the NARSSA Act charges NARSSA with the responsibility to make public and non-public records available and to encourage their use by the public and the state, and to promote the preservation and use of the national archival heritage. Kirkwood (2002) contends that both PAIA and the NARSSA Act significantly promote access to public archives. Ngoepe and Makhura (2006) concur that the NARSSA Act and PAIA share a common vision, namely security and access to primary information source. 
Following an outcry by civil society organisations in South Africa that an oversight role and enforcement of the PAIA appear to have been delegated to the courts, rendering it expensive and time-consuming, Parliament approved amendments to the Protection of Personal Information Act (POPI) and PAIA in order to provide for the establishment of the information commissioner, known as the Information Regulator (IR). An argument was made by several scholars that the SAHRC was no longer able to cope with the workload of monitoring PAIA. Through the PAIA mandate, the SAHRC was identified to be one of the organisations contributing to records management in the public sector. Although PAIA oversight was shifted from the SAHRC to the IR, access to information is still a human right and, as such, the SAHRC could not be fully detached from the PAIA mandate. This research paper argues that a properly documented relationship that has already been observed between NARSSA and the AGSA may also be extended to the newly established IR with a common goal of strengthening stakeholder relationships for the betterment of records management in the public sector.

While the assertion by Mojapelo and Ngoepe (2017) is noted, namely that the successful implementation of PAIA is solely dependent on the status of records management in the public sector, there is a need for the organisations responsible for the monitoring of access to information (IR) to collaborate with the organisations responsible for archives and records management (NARSSA) in order to confront challenges of records management in the public sector in South Africa. Khumalo and Baloyi (2019) postulate that FOI and records management cannot be separated. It is evident that NARSSA is not coping with the regulatory role of the records management in the public sector. For example, in a consolidated PAIA and records management audit report, the SAHRC (2012) indicated that some of the public officials responsible for records management in their respective offices did not even know what was required of them in terms of records management. The fact that public officials do not understand their records management responsibility may be linked to a lack of support from NARSSA. Archival Platform (2015) reports that in 2014, NARSSA was not able to train a single records manager due to a lack of financial resources. It would appear that the advice of Ndenje-Sichalwe, Ngulube and Stilwell (2011) that "funding is key to formulating and implementing an effective records and archival service", fails to reach the ears of those in political power. Perhaps the issue of a lack of funding would soon be history, as the Minister of Finance, Mr Tito Mboweni, indicated in his 2019 budget speech that "officials from the National Treasury and Department of Arts and Culture will consider a proposal for the financial support for the National Archives and other entities" (Mboweni 2019). Balogun and Adjei (2019) advise that public institutions should consider other alternative funding, but, most importantly, should also strive to generate income on their own.

\section{Problem statement}

The persistent poor state of record-keeping in the public sector has a negative impact on the protection of citizens' fundamental human rights, more especially the rights of access to information. The SAHRC (2018) continues to receive complaints against local government and "these complaints emanate from deemed refusal where public bodies do not acknowledge or respond to information requests". To some extent, information requests are delayed due to poor systems in place to support the quick provision of access to records. Although the responsibility to ensure proper records management in the public sector resorts under NARSSA, it is evident that NARSSA is not coping with its oversight responsibility for management and care of records in the public sector. The challenges attached to records management in the public sector 
in South Africa are similar to challenges faced by other countries. Mutula and Wamukoya (2009:5) cite insufficient skills, lack of awareness of the importance of records management, lack of freedom of information (FOI) legislation and limited funding to institutions with the statutory responsibility for records as common challenges faced by many countries around the world.

The lack of a clear framework to express the relationship between records management and access to information poses a major risk for the sustainability of freedom of access to public information. It does not only limit access to public information, but also jeopardises possible collaboration among entities with a common interest to promote sound records management in the public sector. Sebina (2006) posits that freedom of information is adopted on the assumption that good records management is in place to guarantee access to such information. However, this is not always the case, as records management in the public sector has been found inadequate to support many aspects of accountability and transparency, such as auditing, protection of basic human rights and mitigating possible risks (Ngoepe 2014). The issue of freedom of information is more popular, receiving attention from politicians and policymakers; however, records management as an enabler of freedom of information is not receiving enough recognition. The study seeks to explicitly describe how the IR can strengthen the public record management through potential collaboration with the relevant stakeholders as it is evident the poor recordkeeping in the public sector compromises the mandate of the IR.

\section{Research objectives}

The specific objectives are to:

- outline the relationship between the mandate of IR and records management in the public sector

- clarify the records management role to be played by the IR

- propose a framework to improve records management in the public sector through the IR.

\section{Literature review}

The importance of records management in bettering the administration cannot be overemphasised. For example, the International Council on Archives (ICA) (2016), which is an international organisation advocating for the promotion of preservation of records and archives worldwide, believes that "effective records and archives management is an essential precondition for good governance, the rule of law, administrative transparency and access to information by citizens". According to the ISO (2001), records contain information, which is a valuable resource, and should be treated like any other assets in the organisation. However, evidence suggests that such importance is not receiving full recognition, as several scholars such as World Bank (2000), Marutha and Ngulube (2012) and Marutha (2018) and have lambasted the poor records management conditions in the public sector in South Africa. The World Bank (2000) asserts that records management in the public sector in some countries is weak and has actually collapsed. Marutha (2018) underscores that medical records officials in the Limpopo province are struggling to retrieve the required information timeously due to poor records management systems in place. 
As part of PAIA monitoring, the SAHRC regularly conducts training countrywide, where deputy information officers (DIOs) are trained in respect of PAIA. Although the government accepts that the process of access to public information may be cumbersome, section 17 of PAIA directs government entities to designate someone to be a DIO, and the incumbent should assist members of the public with information requests. Ngoepe and Makhura (2006), as well as Mojapelo (2017) observe that some of the DIOs in government departments are records managers. This shows a close relationship between access to information and records management, as the current practice seems to suggest that one needs to have a records management background in order to render access to information service.

The establishment of the IRSA was celebrated by records management and PAIA experts in view of the overarching argument that the SAHRC did not have enough powers to regulate PAIA. On the other hand, several scholars such as Ngoepe and Keakopa (2011), Dominy (2017) and Mojapelo (2017) questioned the ability of the Department of Arts and Culture (DAC) to support the embattled NARSSA, with some suggesting that NARSSA is inappropriately placed under the DAC. For example, in a qualitative study to assess and compare the current state of archival records systems in two ESARBICA member countries, namely South Africa and Botswana, Ngoepe and Keakopa (2011) recommended that the role of the archival service should be shifted from the DAC to Parliament, as the DAC has dismally failed to transform the archival service.

Subsequently, in a study to investigate the role of chapter 9 institutions to records management in the public sector in South Africa, Mojapelo (2017) concluded that chapter 9 institutions should work closely with NARSSA due to an overlapping of mandates that has already been identified. Similarly, in 2006, an ad hoc committee for the review of chapter 9 institutions and associated institutions was established to investigate the effectiveness and efficiency of the aforementioned institutions and to establish whether they were fulfilling their constitutional mandate (Parliament 2007). According to Parliament (2007), the ad hoc committee found that the mandates of other human rights institutions overlapped with those of other institutions, which resulted in a proposal to establish an "umbrella" human rights body for all human rights institutions. Although NARSSA was not cited in the report, Ngoepe and Keakopa (2011) assert that there are members of the public who believe that NARSSA could have more powers if it was placed under the office of the AGSA, largely because NARRSA is supposed to be the auditors of records management in the public sector and not just observers.

The International Conference of Information Commissioners (ICIC), which is constituted by Information Commissioners and Ombudsmen from across the globe, remains instrumental in discussing the implementation of access to information across the world. The 2019 ICIC was hosted in South Africa by the IR, in partnership with the University of Pretoria (UP). However, and most regrettably, NARSSA was not among the delegates invited to make a presentation at the conference. The conference is a key platform upon which networking, partnerships and collaborations are strengthened and renewed. It would seem that the view of Dominy (2009) that there ought to be an international conference to discuss the role of archival institutions to promote access to information, remains unheeded. Moreover, the exclusion of NARRSA from platforms of that nature ignores what Ngoepe (2017) categorises as "window of opportunities".

A PAIA audit conducted by the SAHRC revealed that records management systems in the public sector have an impact on compliance with PAIA (SAHRC 2012). Van der Berg (2017) 
asserts that compliance with the implementation of PAIA in the public sector has been consistently poor, with records management and a lack of an independent oversight body being the main reasons for poor compliance cited in various reports. The reality is that, when proper records-keeping systems are in place to support the successful implementation of PAIA, the provision of access to the requested information will be effortless. The relationship between corporate records management practice and access to information is also recognised by the Parliament of the United Kingdom (Shepherd 2015).

The advantage of PAIA, like any other FOI around the world, is that legislation provides for penalties to be imposed in cases of non-compliance. For example, the Canadian Access to Information legislation was first passed in 1983; however, in 1998 the government realised the Act needed to be amended to provide for penalties for deliberate non-compliance with the act (Millar 2003). This is also the case with PAIA, as it provides for penalties and fines under section 90. The NARSSA Act also provides for penalties; however, there are few instances where the government was taken to court to challenge a decision taken pertaining to records management. With regard to PAIA, in a matter in Jan van der Merwe and other vs National Lottery Board, the applicant (Jan Van der Merwe) argued that the conduct of the respondent (National Lottery Board) to refuse to give access to information was in conflict with the provisions of PAIA. However, the applicant did not have enough records to prove their case and the court ordered that the application be dismissed with cost. On the company website, the IR lists other cases relating to freedom of information which were referred to court for settlement.

The paper highlights the ingredients necessary in creating a viable access to records in the public sector, as provided for under the PAIA and the NARSSA Act.

\section{Findings and discussions}

Findings are presented thematically according to research objectives.

\subsection{Mandate of the IR and the relationship with records management}

\subsubsection{Right of access to records}

In terms of section 11 of PAIA, members of the public should be given access to public records if their requests comply with all the procedural requirements as outlined in PAIA. Section 11 further stipulates that the request for access to records should not be denied unreasonably. Arko-Cobbah (2008) points out that, naturally, secretive public servants normally use a lack of resources or any other reason considered convenient for the effective denial of access to public records. A government that is serious about providing wide access to public information will have to improve the management of records and information. Section 11 of PAIA can be successfully implemented if there are systematic filing systems in place to support the information requests.

\subsubsection{Manuals}

As per section 16 of the Act, public bodies are required to compile section 14 manuals within six months after the commencement of this section or the coming into existence of a public 
body. Section 14 of the Act lists a number of issues to be covered in the manual, such as sufficient detail to facilitate a request for access to a record of the body, a description of the subjects on which the body holds records and the categories of records held on each subject. In the context of records management, what section 14 requires is something similar to a records classification system (file plan). A file plan is a list of records created in an organisation.

\subsubsection{Deputy information officer}

As pointed out earlier, section 17 of PAIA provides for a public body to designate a number of persons as DIOs. The role of a DIO is to ensure that the process of the request for access to information is made easy for the requester of such information. According to the Public Service Commission (2007), the appointment of a DIO is thus the foundation for the successful implementation of PAIA. The provision of section 17 of PAIA on the appointment of a DIO reaffirms the government's commitment to accelerate access to public information. Adeleke (2013) asserts that most public institutions in South Africa do not put measures in place to balance the demand and supply of information. Without the DIO, access to information may be affected, as members of the public may not have the capacity to make requests. Eventually, freedom of information will not be guaranteed (Khumalo, Mosweu \& Bhebhe (2016). It is of paramount importance that public entities assign the responsibilities of a DOI to someone who has the necessary skills to preserve, manage and retrieve records. Mojapelo (2017) asserts that, in some instances, records managers are considered for the role of DIO in South Africa as part of government's commitment to accelerate access to information.

\subsubsection{Records disposal}

Section 21 of PAIA provides for the information officer (IO) to "take steps to preserve records without deleting information contained in it". In terms of the legislation framework in South Africa, no public record should be destroyed, deleted or transferred to an archival repository without approval from NARSSA. For example, in terms of section 13(2)(a) of NARSSA, "no record under the control of a government body shall be transferred to an archives repository, destroyed, erased or otherwise disposed of without written authorisation of the National Archivist". The approval of records to be destroyed, deleted or transferred to an archival repository is necessary to ensure that records are always traced when the request for access is received from members of the public for accountability reasons. If the disposal of records is not regulated, access to information may be hampered.

\subsubsection{Records not found}

PAIA provides for an extension to allow the DIO enough time to search for misplaced records. Moreover, the Act also allows the IO to notify the requester if the information cannot be found. For example, section 23 of PAIA points out that, if the requested record cannot be found, the IO should write an affidavit notifying the requester that it is not possible to provide the information. In the event of failure to give reasons, it could be presumed that access to such information is denied. With the Fourth Industrial Revolution looming, the South African government should invest in technology to manage records. In 2014, the SAHRC received a number of complaints against public bodies that have declined requests for access to records on the grounds that the records do not exist (SAHRC 2015). 
In a study to investigate the relationship between corporate governance and records management in the context of higher education in sub-Saharan Africa, Phiri and Tough (2018) found that South African universities rely on technology to manage records for long-term preservation. Good records management and information management infrastructure are a prerequisite that maintains open government (Svạ̈rd 2018). Section 13 of the NARSSA Act is clear in terms of records classification to be adopted by public entities. According to section 13 of the NARSSA Act, every records classification system to be adopted by governmental bodies should be approved by the National Archivist. A good records classification system allows quick retrieval of records and if used adequately, such a system may prevent files from going missing or being misplaced. NARSSA recommends that governmental bodies use a functional subject file plan, meaning, the file plan must be based on the functions of the organisation.

\subsection{Records management role to be played by the IRSA}

As highlighted, the successful delivery of the PAIA mandate is dependent on the management of records in the public sector. Thus, the current study challenges the IR to consider playing the following role to improve the state of records in the public sector.

\subsubsection{Workshops}

PAIA requires the IR to inform members of the public of their rights of access to information. DIOs also have to be capacitated to be in a position to help members of the public. In monitoring PAIA, Mojapelo (2017) highlights a number of initiatives undertaken by the SAHRC to promote PAIA compliance. Some of the initiatives include the establishment of a National Information Officers Forum (NIOF), Golden Key Awards and PAIA workshops. However, in a study to investigate the role of the SAHRC for records management in the public sector, Mojapelo and Ngoepe (2017) found that the SAHRC was not doing enough to infuse records management aspects into PAIA workshops. It was noted that records management issues were raised in the workshops, but the actual training on records management did not form part of the workshop. Nevertheless, the IR can adopt a new strategy and foster the inclusion of records management aspects in PAIA workshops. This can be done in collaboration with NARSSA. Evidence suggests that the SAHRC is investing more on workshops; this is also expected to be seen with the IR.

\subsubsection{Consultation}

PAIA provides for the IR to consult with relevant stakeholders interested in issues of access to information. In the process of consultation, the IR is required to obtain advice and consider proposals or recommendations from public or private bodies. For the purpose of consultation, the IR may consider engaging with NARRSA to address records management issues affecting the public sector. NARSSA can provide the necessary advice on technical issues which may be cumbersome for the IR to address. Consultation, in the context of this paper, should be seen as a strategy to engage with relevant stakeholders such as NARSSA to discuss ways in which access to public information can be made more user-friendly as a result of good record-keeping. 
Section 84 of PAIA directs the SAHRC (now the IR) to report to Parliament on issues pertaining to PAIA. In terms of section 84 of PAIA, some of the issues to be covered include the following:

- Number of requests for access received, granted in full, granted in terms of section 46, and refused.

- Number of cases which were referred to court and the court decisions

- Number of complaints lodged with the public protector.

One would expect the IR to also include in the report issues regarding the management of records in the public sector. As part of the report to Parliament, the IR may consider other aspects of access to information, such as records management. Some of the aspects to report on are the record-keeping systems adopted by government entities and establishing whether the records classification systems are approved by the relevant structures in government. The NARRSA Act requires that NARSSA should perform records inspections regularly, and it is therefore argued in this paper that such inspection reports may be shared with the IR for the purpose of reporting to Parliament. As some of the challenges faced by the public sector records management emanates from limited funds, the IR, through the report to Parliament, may record such challenges for Parliament to note and intervene. Adeleke (2016) postulates that a weakness of PAIA is that the Act (PAIA) does not require public entities to develop implementation plans that can be used to assess the compliance performance of each entity. The implementation plan is necessary for the purpose of reporting.

\section{Proposed framework}

The study proposes a framework as mapped out in figure 1 to demonstrate how records management in the public sector can be strengthened through the IR. As shown in figure 1, records management has an impact on both mandates of the information regulator, although the current study is only focusing on the PAIA mandate. In terms of PAIA, the IR is expected to perform in the following fields: education, consultation, report, code of conduct and appointment of DOIs. The proposed framework shows how each functional area is related to records management in the public sector. On education, the proposed framework shows that the IR can render workshop services on good practice in terms of records management. As part of consultation, the IR will consult with the relevant structures such as NARSSA and the AGSA to address issues of common interest (records management). Reports to be submitted to Parliament, as PAIA dictates, should also cover other aspects of records management. Several challenges experienced by the public sector regarding records management should be recorded in the report for Parliament to intervene. PAIA requires that the IR should develop a code of conduct on access to information; therefore, it is argued in this paper that records management aspects such as records disposal, records classification systems, records appraisals, and everything to do with good practice should be included in the code of conduct. 


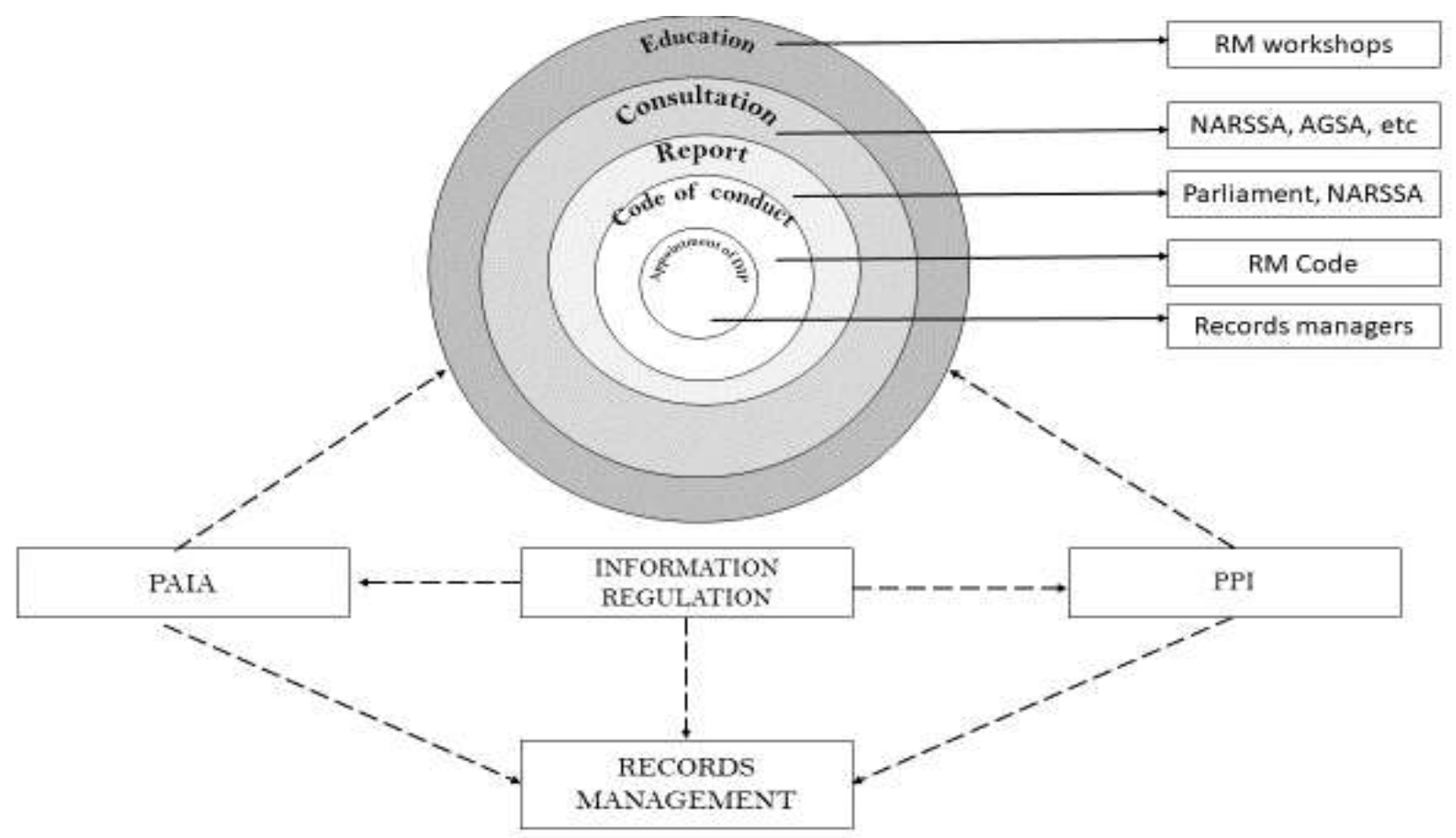

Figure 1: Proposed framework to strengthen public sector records management through the Information Regulator in South Africa

The proposed framework will go a long way in addressing the challenges faced by the public sector in terms of records management. The proposed framework explicitly describes how the IR can support NARSSA by making a contribution to the strengthening of records management in the public sector. The proposed framework describes specific powers and functions of the IR as outlined in PAIA with the intent to describe how each function connects with records management in the public sector.

\section{Conclusion}

It is clear from the discussion and findings that there is a solid relationship between records management and access to information in the sense that, without proper record management, there would be limited access to information. As indicated earlier, freedom of access to information is adopted on the assumption that there is proper records management. It has been observed that the IR has already made inroads into the records management space through the facilitation of workshops where records management issues are emphasised. Without necessarily stepping on the toes of the NARRSA, it is recommended that more effort is needed to strengthen the working relationship with NARSSA for the betterment of records management in the public sector.

The looming of the IR presents a "window of opportunity" for records management in the public sector. It is clear that the IR has more powers than NARSSA, which functions under the direction of the Minister of Arts and Culture. The IR is independent from any government influence, which makes the IR more effective. The IR is expected to perform its functions without fear or any form of intimidation. Public sector records management have been keen for more comprehensive oversight and the supervision from an independent body that well 
capacitated to hold government accountable for non-compliance with archival and records laws and policies.

\section{Reference}

Adeleke, F. 2013. Constitutional domestication of the right of access to information in Africa: Retrospect and prospects. Access to Information in Africa: Law, Culture and Practice 83-105.

Adeleke, F. 2016. The role of the right to information in the contestation of power in South Africa's constitutional democracy. Southern African Public Law 32(1): 54-72.

Archival Platform. 2015. State of archives: An analysis of SA's National Archival System, 2014. Available at: http://www.archivalplatform.org/news/entry/executive_summary/ (Accessed 22 May 2015).

Arko-Cobbah, A. 2008. The right of access to information: opportunities and challenges for civil society and good governance. International Federation of Library Associations Journal 23(2): 180-191.

Auditor-General of South Africa. 2015. Consolidated general report on the audit outcomes of local government 2013/14. Pretoria: AGSA.

Balogun, T. \& Adjei, E. 2019. Challenges of digitization of the National Archives of Nigeria. Information Development 35(4): 612-623.

Coetzer, X.P. 2012. The status of records management at the University of Zululand. PhD Thesis, University of Zululand.

Dominy, G. 2009. Access to state archives improves: Whereto now? South African History Journal 25(1): 354-355.

Dominy, G. 2017. The effects of an administrative and policy vacuum on access to archives in South Africa. Archival Science 17(4): 393-408.

International Council on Archives. 2016. About International Council on Archives. Available at: https://www.ica.org/en/international-council-archives-0. (Accessed 29 April 2019).

International Organisations for Standards. 2001. ISO 25489-1: 2001 Records and Documentation - Records Management.

Kirkwood, C. 2002. The Promotion of Access to Information Act (PAIA) and the National Archives and Records Service of South Africa Act: A comparative analysis on the previous and present statutes governing access to archives and public records with a special focus on the implications of PAIA for public archives services. ESARBICA Journal 21: 2-16.

Khumalo, N.B. \& Baloyi, C. 2019. The possible benefits of freedom of information laws to the records management landscape in the ESARBICA region. Information Development 25(2): 176-190.

Khumalo, N.B., Mosweu, O. \& Bhebhe, S. 2016. A comparison study of freedom of information legislation in Botswana, South Africa and Zimbabwe. Mousaion 34(4): 109-131.

Marutha, N.S. 2018. The application of legislative frameworks for the management of medical records in Limpopo province, South Africa. Information Development 35(4): 551-563.

Marutha, N.S. \& Ngulube, P. 2012. Electronic records management in the public health sector of the Limpopo province in South Africa. Journal of the South African Society of Archivists 45: 39-67. 
Mboweni, T. 2019. 2019 Budget speech. South Africa: Treasury. Available at: www.treasury.gov.za/documents/national\%20budget/2019/speech/speeck.pdf (Accessed 26 April 2019).

Mojapelo, M. 2017. The contribution of chapter nine institutions to records management in the public sector in South Africa. Master's dissertation, University of South Africa.

Mojapelo, M. \& Ngoepe, M. 2017. The role of the South African human rights to records management in the public sector. Journal of the South African Society of Archivists 50: $22-55$.

Millar, L. 2003. The right to information - the right to records, the relationship between the recordkeeping, access to information, and government accountability. New Delhi: Commonwealth Human Rights Initiative. available at: www.humanrightsinitiative.org/old/programs/ai/rti/articles/record-keeping-ai.pdg (Accessed 29 April 2019).

Mutula, S. \& Wamukoya, J.M. 2009. Public sector information management in east and southern Africa: Implications for FOI, democracy and integrity in government. International Journal of Information Management 29(5): 333-341.

Ndenje-Sichalwe, E., Ngulube, P. \& Stilwell, C. 2011. Managing records as a strategic resource in the government ministries of Tanzania. Information Development 27(4): 264-279.

Ngoepe, M. 2014. The role of records management as a tool to identify risks in the public sector in South Africa. South African Journal of Information Management 16(1): 1-8.

Ngoepe, M. 2017. Archival orthodoxy of post-custodial realities for digital records in South Africa. Archives and Manuscripts 45(1): 31-44.

Ngoepe, M. \& Keakopa, S.M. 2011. An assessment of the state of the national archival and records systems in the ESARBICA region. Records Management Journal 21(2): 145160.

Ngoepe, M. \& Makhura, M. 2006. Assessing the extent of compliance with regard to National Archives and Records Service of South Africa Act and Promotion of Access to Information Act: Implications for good governance and accountability. ESARBICA Journal 25: 128-138.

Parliament of the Republic of South Africa. 2007. Report on the Ad Hoc Committee on the review of chapter nine and associated institutions. South Africa: Parliament of the republic of South Africa.

Phiri, M.J. \& Tough, A.G. 2018. Managing university records in the world of governance. Records Management Journal 28(1): 47-61.

Public Service Commission. 2007. Implementation of the Promotion of Access to Information Act (Act No 2 of 2000) in the Public Service. Pretoria: PSC.

Sheperd, E. 2015. Freedom of Information, Rights to Access Information, Open Data: Who is at the table? The Commonwealth Journal of International Affairs 104(6): 715-726.

Sebina, P.M.I.M. 2006. Freedom of information and records management: A learning curve for Botswana. PhD thesis, University of London, London.

South African Human Rights Commission. 2012. The Promotion of Access to Information Act (PAIA) and records management consolidated audit report: 2008-2012. Available at: https://www.sahrc.org.za/home/21/files/Consolidated\%20PAIA\%20Audit\%20Report $\% 202012$. doc2.pdf (22 October 2019).

South African Human Rights Commission. 2015. Promotion of Access to Information Act Annual Report 2014-2015. Johannesburg: SAHRC.

South African Human Rights Commission. 2018. Promotion of Access to Information Act: (PAIA) Annual Report 2017/18. Johannesburg: SAHRC. 
South African Government. 1996. The Constitution of the Republic of South Africa Act No. 108 of 1996. Republic of South Africa.

South African Government. 1996b. National Archives and Records Service of South Africa Act No 43 of 1996. Republic of South Africa Government Gazette, vol. 451, No. 17471

South African Government. 2000. Promotion of Access to Information Act No. 2 of 2000. Republic of South Africa Government Gazette, vol 39504, No. 1222.

Svärd, P. 2018. Has the Freedom of Information Act enhanced transparency and the free flow of information in Liberia? Information Development 34(1): 20-30.

Van der Berg, S. 2017. Strengthening access to information institutions to promote a culture of transparency. South African Journal on Human Rights 33(2): 169-192. DIO: 10.1080/02587203.2017.1346560 (Accessed 28 April 2019).

World Bank. 2000. Managing records as the basis for service delivery: an introduction to core principles staff of the World Bank as its partners. International Records Management Trust: London. Available at: siteresources.worldbank.org/EXTARCHIVES/Resources/Core\%20Principles.pdf (Accessed 8 August 2019). 